\title{
Chapter \#: Enhancing Learning with Visualization Techniques
}

\author{
Joris Klerkx, Katrien Verbert, Erik Duval \\ Katholieke Universiteit Leuven, Belgium
}

\begin{abstract}
The use of visualization techniques in learning is not new. They have been used in maps and drawings for thousands of years. This chapter analyzes how more novel visualization techniques can be used to enhance various activities during the learning process: finding and understanding educational resources, collaboration with learners and teachers, (self-) reflecting about learners' progress, and designing learning experiences. We illustrate our analysis with example tools and visualizations. Results of our analysis indicate that visualization techniques are beginning to be more widely used for learning but further research is needed to assess the added value of these visual approaches in terms of effectiveness, efficiency or other criteria that pertain to learning.
\end{abstract}

\section{Keywords}

Information Visualization: The use of computer-supported, interactive, visual representations of abstract data to amplify cognition (Card, Mackinlay, \& Sheiderman, (1999).

Collaborative Learning: A situation in which two or more people learn or attempt to learn something together (Dillenbourg, 1999). 
Klerkx, Verbert \& Duval

Learning Analytics: The measurement, collection, analysis and reporting of data about learners and their contexts, for purposes of understanding and optimizing learning and the environments in which it occurs

Learning Design: the application of learning design knowledge when developing a concrete unit of learning, e.g. a course, a lesson, a curriculum, or a learning event (Koper \& Tattersall, 2005). 


\section{Chapter \#: Enhancing Learning Using Visualization Techniques}

\section{Introduction}

The use of visualization to present information is not new. It has been used in maps and drawings for thousands of years. One famous example is Ptolemy's world map (see Figure 1) that has been created somewhere in the second century BC. Today, the field of visualization has become quite a bit more diverse, with applications such as scientific visualization (Shneiderman \& Bederson, 2003), knowledge visualization (Burkhard \& Meier, 2005) and visual analytics (Keim et al., 2008).

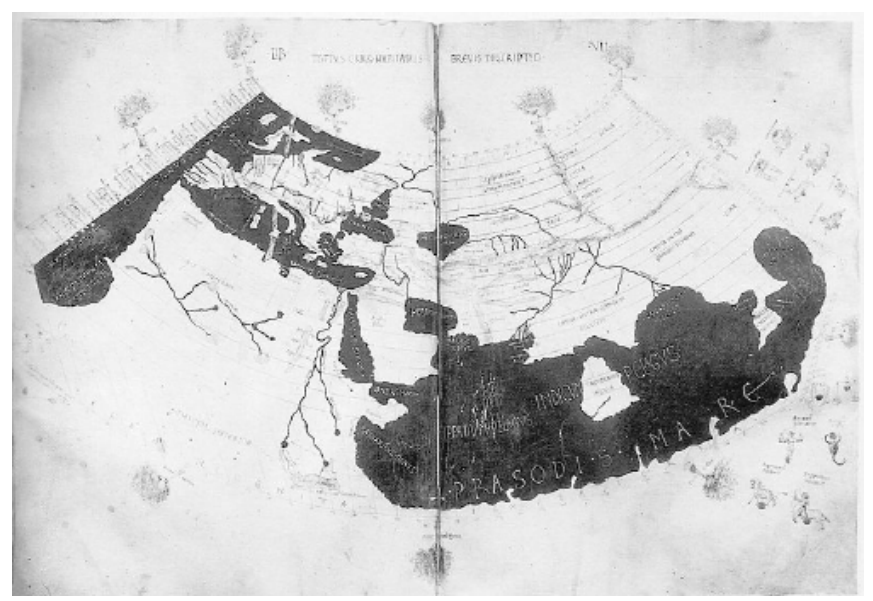

Figure 1: Reconstituted Ptolemy's World Map - The British Library Harley MS 7182,_58v-59

Information visualization research is focused on enabling users to control the process of flexibly navigating through information spaces of abstract data, for which there may be no inherent mapping to space or a natural physical reality (Card, Mackinlay, \& 
Klerkx, Verbert \& Duval

Shneiderman, 1999). Existing visualization techniques cover a wide spectrum of application domains. An increasing number of artists and designers have applied these techniques as a powerful and even artistic means of expression (Vande Moere \& Purchase, 2011).

This chapter investigates how such visualization techniques are currently being used to support learning. We structure the chapter around five basic activities in the learning process:

- Find-How can visualization add value when learners or teachers are searching for relevant learning material about a certain topic?

- Understand - How can visualization facilitate better understanding of the subject matter of learning material?

- Collaborate - How can visualization support collaboration among learners? How can visualization support collaboration between learners and their teachers?

- (Self-)Reflect - How can visualization help learners reflect on how they are doing in a running course when compared with other learners? How can it help teachers gain insight into achieving desired learning outcomes?

- Design - How can visualization facilitate the design of learning experiences?

This chapter begins with a background section, aimed at providing the reader with relevant pointers to the basic literature on information visualization techniques. The following sections will then discuss the context and meaning, and the current use of visualization techniques for supporting each of the activities described above. Future directions for this area of inquiry and promising research opportunities are discussed in the concluding section. 


\section{Background: Information Visualization}

Nowadays, there is an abundance of available data and information on the Web. However, it is only when this data is understood that it becomes valuable, not when it is just made available (Few, 2009). Information visualization is a powerful means of making sense of this data (Heer \& Shneiderman, 2012) that has emerged from research in human-computer interaction, computer science, graphics, visual design, psychology, and quantitative data analysis. It is a growing field that is increasingly applied as a critical component in scientific research, digital libraries, data mining, financial data analysis, market studies, manufacturing production control, and drug discovery (Shneiderman \& Bederson, 2003). The aim of this section is to assist the reader who is new to the field of information visualization to become aware its foundational literature.

The main intent of information visualization is to represent an abstract information space in a dynamic way, so as to facilitate human interaction for exploration and understanding. It relies on the design of effective and efficient --as well as sometimes playful and aesthetically pleasing-- interactive visual representations that users can manipulate for open-ended exploration or to solve specific tasks. This approach is especially useful when a person does not know what questions to ask about the data or when she wants to ask better, more meaningful questions (Fekete, Van Wijk, Stasko, \& North, 2008). Information visualization makes use of the principles in Gestalt Theory regarding the human visual capacity as a powerful pattern-finding engine, to provide a powerful means of making sense of the abundance of available data. For example, the principle of spatial proximity posits that humans instinctively group data points that are perceptually close together. Visual connectedness between data points in the form of an edge between two nodes provides an even stronger relationship. Ware (2004) provides a thorough 
Klerkx, Verbert \& Duval

explanation of other Gestalt principles such as similarity, continuity, symmetry, closure and relative size.

In order to visualize a data set, one needs to create a visual representation or encoding of one or more of its data attributes or types. It involves mapping these attributes to visual features like shape, size, orientation, etc. (Ware, 2004). Several data type taxonomies have therefore been described in the literature (Chi, 2000; Ellis \& Dix, 2007; Keim, 2002; Adnan, Daud, \& Noor, 2008), which can be used as guidelines during the visual encoding process. For each data type, appropriate visualization techniques and tasks have been designed (Shneiderman, 1996). The following list presents them, together with original publications that describe the techniques in detail:

- for 1-dimensional data: fisheye views (Furnas, 1999), sparklines or line charts (Willett, Heer, \& Agrawala, 2007);

- for 2-dimensional data: spatial displays such as dense pixel displays (Keim, 2000), heatmaps (Pryke, Mostaghim, \& Nazemi, 2007), and the like;

- for 3-dimensional data: architectural renderings or metaphoric worlds (Santos et al., 2000);

- for temporal data: timeline visualizations such as theme rivers (Nowell, Havre, Hetzler, \& Whitney, 2002), clustered time series (Van Wijk \& Van Seelow, 1999) or time matrices (Yi, Elmqvist, \& Lee, 2010);

- for hierarchical data: stacked displays such as tree-maps (Shneiderman \& Johnson, 1991), hyperbolic trees (Lamping \& Rao, 1996), dendograms, cone and radial trees (Nussbaumer, 2005);

- for network data: node-link diagrams (Elmqvist \& Fekete, 2010) with graph layout algorithms such as Reingold and Tilford, H-trees and Balloon graphs (Herman, Melancon, \& Marshall, 2000); and 
- for multidimensional data: scatterplots, elastic lists (Stefaner, Urban, \& Marc, 2008), parallel coordinates (Inselberg, 1985), data meadows (Elmqvist, Stasko, \& Tsigas, 2008), and the like.

These taxonomies have been widely accepted and assist designers to choose appropriate visual representations for their data set. However, these representations often require dynamic interactions to figure out what the data means. Hence, they have been mapped against interaction technique taxonomies that consider interactive filtering, zooming, distortion, linking and brushing, etc., as well as task taxonomies for visualization interfaces such as overview, zooming, filtering, panning, details-on-demand, relating, history, extract, sort, comparing and more (Keim, 2002; Heer \& Shneiderman, 2012; Few, 2009). The purpose of these filtering techniques is to remove information that is irrelevant and therefore distracting from the task at hand (Few, 2009). In the following sections, we will show how combinations of these techniques are used to support various activities in the learning process.

\section{Finding Learning Material}

High quality learning materials such as texts, graphical illustrations, interactive demonstrations, tutorials, and audio and video presentations are essential for students to fully grasp and understand the meaning of a certain topic. To locate these materials for their classes, teachers often turn to conventional Web search engines such as Google, Yahoo! and others, or to so-called learning object repositories (LORs) such as GLOBE "www.globe-info.org", an international network that interconnects networks of LORs. Such repositories contain learning materials that were produced by professional publishers or fellow teachers. The main advantage of searching these LORs is that the materials are often described with useful educational metadata such as intended target audience, learning time, etc., that can help to quickly find the material a user is looking 
Klerkx, Verbert \& Duval

for. Teachers -- but also students who want to find relevant material independently from their teachers -- typically express their information need as simple or advanced queries by filling out electronic forms. These enable them to compose Boolean combinations of search criteria. However, queries typed into search boxes are not effective enough to meet all the demands (Marchionini, 2006). Both web search engines or LORs present a ranked list of results to the users. Teachers can evaluate the results in this list and, if necessary, reformulate the query to filter out some results or include some more. This process of formulating queries and evaluating the results can be lengthy and is rather time-consuming and user-unfriendly (Duval \& Hodgins, 2003). The intersection of information visualization and search interfaces, where rich presentation of search results can enable exploration, insight and understanding (Morville, 2005; Ahn \& Brusilovsky, 2009), is therefore especially relevant to this section. We will provide pointers to example visualization techniques that can be used to flexibly and efficiently get access to a collection of educational resources.

We found that visual designers frequently use the hierarchical classification of the subject of the educational resources. For example, the classification of a resource that explains the algorithm of the "Towers of Hanoi" (Buneman \& Levy, 1980) could be:

- Exact, Natural and Engineering sciences;

- Informatics/Information Processing;

- Recursion;

This hierarchical classification is then visualized in a so-called stacked display, which is tailored to present data partitioned in a hierarchical fashion (Keim, 2002). As such, these stacked displays provide a visual overview about the subjects or topics of the materials that are covered in such a collection. For example, Bouzeghoub et al. (2009) presented the classification overview as a Venn diagram, although earlier studies (such as 
Rivadeneira \& Bederson, 2003) showed that without extra hierarchical cues, users quickly lose orientation in such a display. Klerkx, Duval, and Meire (2004) and Clarkson, Desai, and Foley (2009) have both used tree-map visualizations to present this hierarchical information. Figure 2 shows a combination of this kind of stacked display with a filtering mechanism that enables end users to manipulate several controls over the metadata, zoom in on potentially more relevant material while still having access to an overview of how additional search criteria will restrict the remaining number of learning objects. An evaluation of this prototype has been conducted to measure its effectiveness (i.e. correct results) and efficiency (i.e. fast results). Task time, task accuracy and user satisfaction were measured in an experiment where the visual prototype and a traditional tool for finding educational resources were compared. Results indicated that the visualization design helped users to easily keep track of the number of matching results.

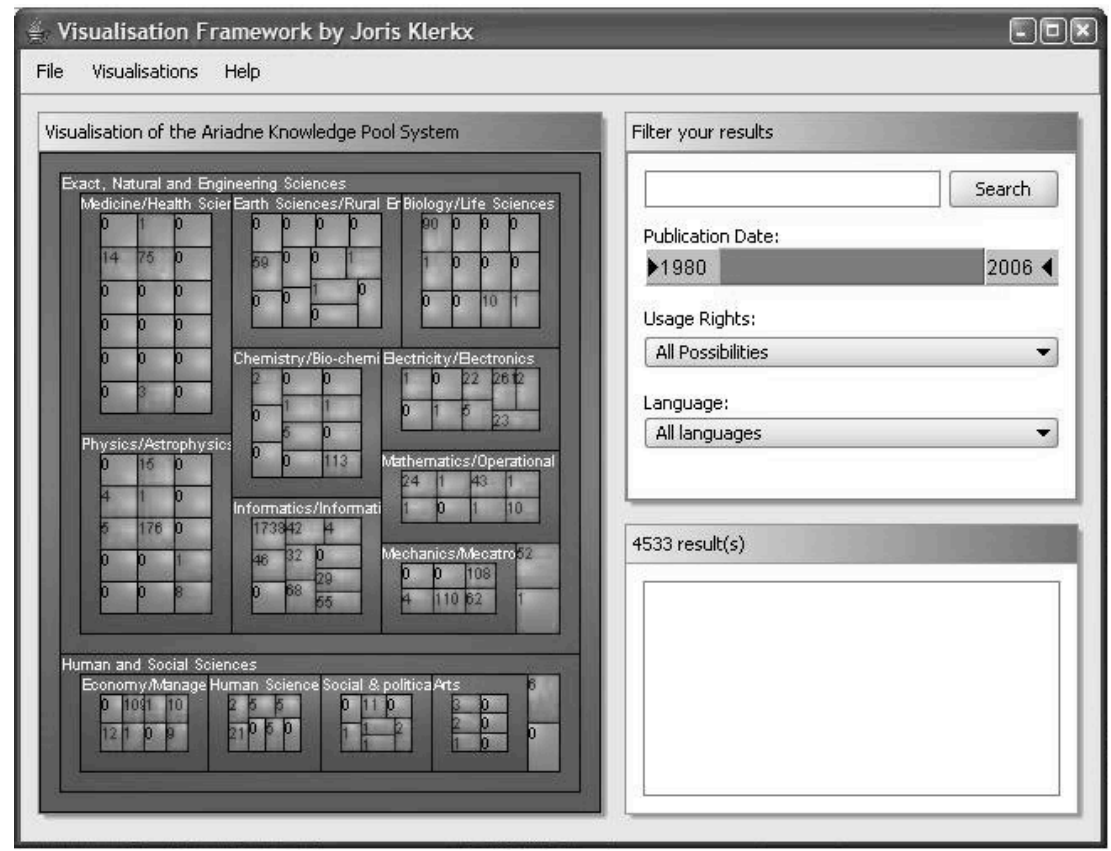

Figure 2: Providing visual access to educational resources. On the left side, one can see an overview of the educational resources, classified by their topic description. Users can click on any 
Klerkx, Verbert \& Duval

of the groupings such as Medicine/Health Sciences to zoom in on its sub-categories. The numbers in each square indicate the number of matching resources in a category, compared with controls of the filter mechanism on the right (adapted from Klerkx, et.al, 2004).

However, most users also needed time to get acquainted with navigating the tree-map visualization. Consequently, this prototype had a higher learning curve than a more traditional search tool. These results were confirmed in (Kobsa, 2004) and (Wang, Teoh, $\& \mathrm{Ma}, 2006)$. From those evaluations, it can be concluded that the use of information visualization techniques is a useful alternative to more traditional ways of accessing learning object repositories. However, a number of recommendations were made in these studies to ensure that users know how to use the visualizations. For instance, adding navigational cues are important: if a user searches for "history," the resulting learning objects should be clearly highlighted in the visualization.

The applications presented in Sumner et al. (2005), Dicheva and Dichev (2006), Lee, (2007) and Lalingkar and Ramani (2010) differ from the examples above, in that the applications do not provide visualizations of the metadata of the resources, but rather the resources' external ontologies --such as learning goals and subject domains. All of them created a graphical topic map browser for these ontologies. These are basically node-link graphs -- discrete structures that consist of nodes or vertices at the one hand and links or edges at the other hand. Vertices correspond to the objects and the edges correspond to the relations between the objects. An example node-link graph can be seen in Figure 6. In the applications above, teachers or students typically have to navigate these graphs and select those nodes that correspond with the subjects they are searching information on. Only when an interesting topic is selected, a query is issued to the repository of educational resources to see if there are potential matching resources. The drawback of this approach is that the user does not receive continuous feedback about how many resources still satisfy his criteria: the result is that users may loose time further refining criteria when the issued query does not return relevant resources in the result set, or, 
conversely, may consider the refinement process finished when still too many resources are included in the result.

\section{Discussion}

The examples that have been presented above show how visualization can help teachers and students to find relevant material when they are searching for instructional materials. Lab tests with small numbers of users indicate that the techniques make the process of finding resources more efficient. However, to our knowledge, no extensive user tests in real-life settings were executed to measure the success or impact of these tools. Also in other domains, attempts to use information visualization to improve search has not yet proven itself. However, as Hearst (2009) argued, "This is not to say that advanced visual representations cannot help improve search; rather that there are few proved successful ideas today" (Ch. 10, "http://searchuserinterfaces.com/book/").

\section{Understanding Subject Matter}

Once a relevant educational resource has been located, it is essential that it actually helps learners to grasp or understand its subject matter. The aim of this section is to present a number of successful case studies that use visualization techniques for provoking understanding of their meaning.

Mendeleev's periodic table of elements, which encodes several types of data in a small table format, is probably one of the most famous examples of visualization used in educational contexts (see Figure 3). 
Klerkx, Verbert \& Duval

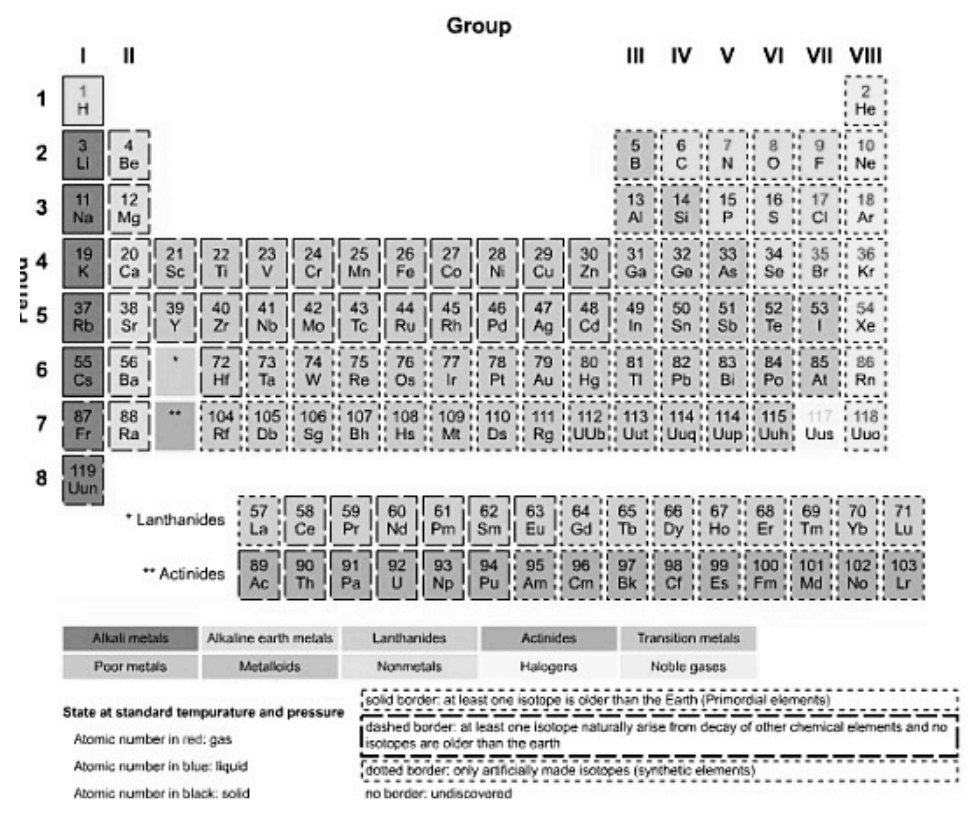

Figure 3: Mendeleev's periodic table of elements (from Steele \& Iliinsky, 2010).

This visualization is informative, efficient and can be considered one of the earlier beautiful visualizations of complex chemistry data (Steele \& Iliinsky, 2010). Mendeleev's periodic table visualization is known by millions of students all over the world and is a perfect example how visualization can be effectively used to support understanding of subject matter.

There are many successful examples of this kind in education. Studies have also demonstrated the effectiveness of these visualizations. For example, in computer science education, there is a long history of data and algorithm visualizations and animations (Shaffer, Cooper, \& Edwards, 2007). The AlgoViz ${ }^{1}$ wiki lists 513 different interactive

\footnotetext{
${ }^{1}$ http://wiki.algoviz.org/AlgovizWiki/Catalog
} 
visualizations that help to explain several kinds of programming algorithms, such as sort, graph, compress, and many more ("http://wiki.algoviz.org/AlgovizWiki/Catalog"). These kind of interactive visualizations are often used to explain different aspects of software algorithms to students. For example, Figure 4 shows an interactive java applet that visually explains the bubble sort algorithm (Eck, 1995), which is often used to introduce the concept of a sorting algorithm to introductory computer science students. The algorithm works by iterating over a list of numbers. Starting from the beginning of the list, it compares every pair of items, swaps them if needed, and moves on until the end of the list. Then the iteration starts over until the complete list is sorted. The interactive visualization in Figure 4 allows students to learn this algorithm by stepping through this whole process while it compares, and potentially swaps adjacent bars.

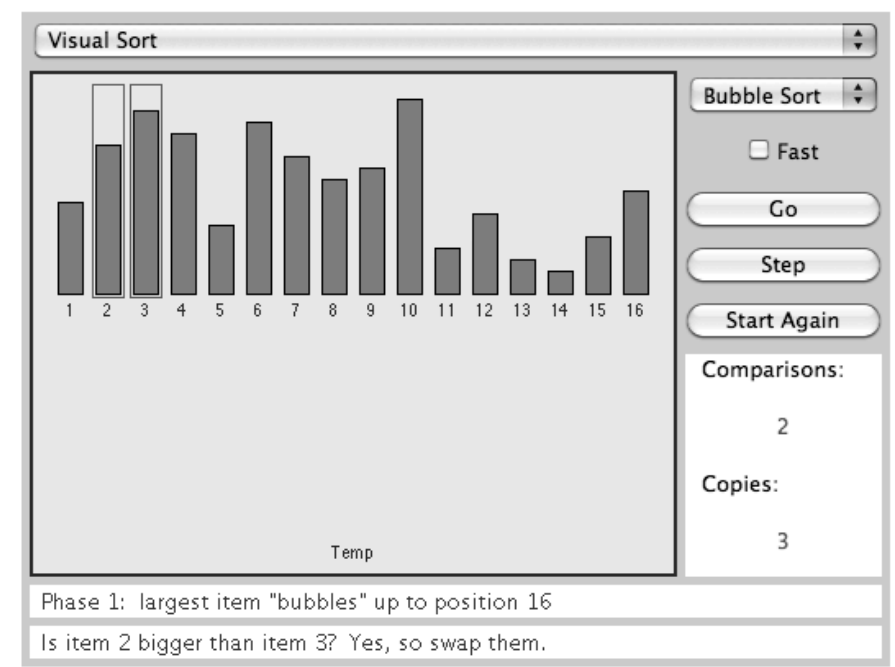

Figure 4: Providing understanding of the inner-workings of the bubble sort algorithm (Eck, 1995) Hundhausen, Douglas, and Stasko (2002) did a meta-analysis of 24 studies on algorithm visualization effectiveness. About half of these studies reported no significant effect of the visualization on the performance of students. About half however did report a positive, significant effect. One study reported a significant negative effect. The authors 
Klerkx, Verbert \& Duval

relate the algorithm visualizations to four "theories of learning" (epistemic fidelity, dualcoding, individual differences and cognitive constructivism). Cognitive Constructivism proposes that learning is an active process where learners construct their knowledge through experience (Kanuka \& Anderson, 1999). It has been the most tested of these theories, and algorithm visualization studies utilizing tools that are grounded in constructivist pedagogical approaches have obtained the greatest number and highest percentage of significant differences. As such, cognitive constructivism has gathered the most consistent empirical support in the studies they reviewed. The meta-analysis is inconclusive however on the question whether algorithm visualizations mainly contribute to conceptual or procedural understanding of algorithms.

Visualizations also play an import role in other learning domains such as mathematics where they enable students to see the unseen in data. Arcavi (2003) argued:

Visualization has a powerful complementary role for mathematics students in three aspects: as (a) support and illustration of essentially symbolic results, (b) a possible way of resolving conflict between (correct) symbolic solutions and (incorrect) intuitions, and (c) as a way to help us re-engage with and recover conceptual underpinnings which may be easily bypassed by formal solutions (p.223).

It is hard to find any mathematics textbook that does not use visualization techniques for explaining mathematical concepts such as the Pythagorean theorem. Presmeg (2006) provided a thorough review of research on visualization in learning and teaching mathematics since 1980. She stipulated a list of 13 research questions that are of major significance for future research on visualization in mathematics education. She discovered that a neglected area of research is how visualization actually interacts with the didactics of mathematics. The author concluded: 
"Effective pedagogy that can enhance the use and power of visualization in mathematics education (Woolner, 2004) is the most pressing research concern at this period: very few studies have addressed this topic" (p. 234).

\section{Discussion}

The examples above indicate that teachers and learners should consider using visualization techniques in order to facilitate understanding. Naps et al. (2003) have thoroughly surveyed current practice by teachers in computer science. Out of 93 instructors, all agreed that visualizations have the potential to help students as they learn computing concepts. $90 \%$ believed that visualizations make the teaching experience more enjoyable. $86 \%$ had anecdotal evidence of an improved level of student participation. $76 \%$ believed that visualization provides a powerful basis for discussing conceptual foundations. $72 \%$ claimed anecdotal evidence and $52 \%$ claimed objective evidence of improved student learning. However, the same instructors also claim that actually using visualization techniques is hindered because of the time required to search for good examples (93\%), the time it takes to learn new tools themselves $(90 \%)$, the time it takes to develop visualizations $(90 \%)$ or to adapt them to course content $(79 \%)$, and the lack of evidence of the effectiveness of visualizations (59\%). Even if those results cannot be directly generalized to other domains, (Naps et al., 2003) believes that the educational impact in classroom instruction can only be augmented if instructors are induced to integrate visualization techniques in their classes. It seems reasonable to project similar expectations to augmentation of non-classroom situations, including informal learning. 
Klerkx, Verbert \& Duval

\section{Collaborative Learning}

Interactions with peer learners are a core aspect of how learning is organized (Balacheff et al., 2009). This is particularly relevant for Computer Supported Collaborative Learning (CSCL) where learning is not only a matter of accepting fixed facts, but it is the dynamic, on-going, and evolving result of complex interactions primarily taking place within communities of people (Stahl, Koschmann, \& Suthers, 2006). Visualization of a social network can therefore be extremely useful to make people aware of their social context and to enable them to explore this context (Heer \& boyd, 2005). In a CSCL setting, visualization can support learners in coordinating their actions - one potential advantage is that this can help to overcome the so-called over-scripting problem that often occurs in CSCL (Dillenbourg, Järvelä, \& Fischer, 2009). A collaboration script is a set of instructions that describe how students should work together, form groups, and how they should collaborate to reach a common goal such as solving a prescribed problem. Overscripting may interfere with the learning process by forcing students to interact in a nonnatural way (Dillenbourg, 2002). CSCL approaches to visualization vary from mirroring systems, which display basic actions to collaborators, metacognitive tools, which represent the state of interaction via a set of key indicators, and coaching systems, which offer advice based on an interpretation of those indicators (Soller et al., 2005). Especially the first two aspects lend themselves well to visualization approaches, as we will show in the examples below.

Kirschner et al. (2003) presented an overview of how collaborative decision-making through argument visualization can be supported through node-link diagrams where nodes are either arguments or statements and links between the nodes represent inferences between those. Figure 5 shows how DebateGraph is used to facilitate the 
debate on climate changes by visualizing different points of view to comprehend the topic at hand, in this case the environmental debates. Such visualization not only helps the decision-making process in climate change congresses, but it also provokes understanding of various opinions and provides insights how other learners construct their arguments. Users construct these diagrams themselves with such visualization tools. Braak, Oostendorp, Prakken, and Vreeswijk (2006) did a critical review of Belvedere (Suthers, et.al, 1995), Convince me (Schank \& Ranney, 1995) Questmap (Carr, 2003) and Reason!Able (Van Gelder, 2002). They investigated how those tools were evaluated in practice. All evaluations tried to measure the tools' ability to help learners become better reasoners and to improve the quality of their constructed arguments. The authors stated that, while the findings were not significant statistically, they did find a positive trend in this direction.

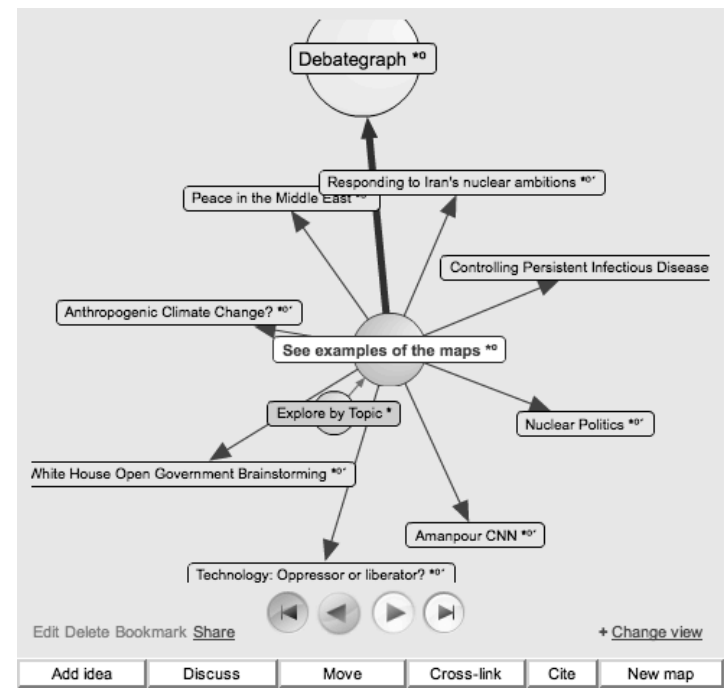

Figure 5: Facilitating argumentation and discussion in CSCL through visualization (created with DebateGraph)

Closely related to collaborative decision-making is collaborative concept mapping; a well-know visualization technique providing an external representation of relationships 
Klerkx, Verbert \& Duval

between concepts relative to a particular topic. Molinari et al. (2008) did an experiment with 58 students to find out how they "refer to," "do something with" or "build upon" other students' contributions in the common concept map. Students were divided in groups of 2 . The 2 students worked with a tool divided into 3 parts where they could see their own concept map, their partner's concept map, and a combined one. Results showed that it took much time and effort for the pairs to visually compare and coordinate their concept maps. Working with two maps instead of one combined concept map therefore seemed to provoke lower learning performance. We can learn from these results that not all visualization techniques provide an added value in each context. Where node-link diagrams work rather well in collaborative decision-making, they do not necessarily enhance collaborative concept mapping. Each specific context therefore needs thorough evaluation in real-life settings to assess added value of these visual approaches.

As a second example, there is a rich body of research on the use of social network analysis (SNA) visualizations to provide awareness of co-workers in ComputerSupported Collaborative Work or research networks (Klamma et al., 2006). With the explosive rise of social networks like FaceBook, google+ or Twitter, and tools based on visual representations of these networks (Heer \& boyd, 2005), we expect that these tools will be widely leveraged where social software is being deployed in collaborative learning environments as well. One example is the Social Networks Adapting Pedagogical Practice (SNAPP) tool that allows users to visualize the network of interactions resulting from forum posts and replies (Dawson, 2009). Figure 6 shows how these kinds of visualizations allow seeing the group dynamics within a learning community in a course and potentially provide insights in which students are, for example, becoming disconnected from the community. 


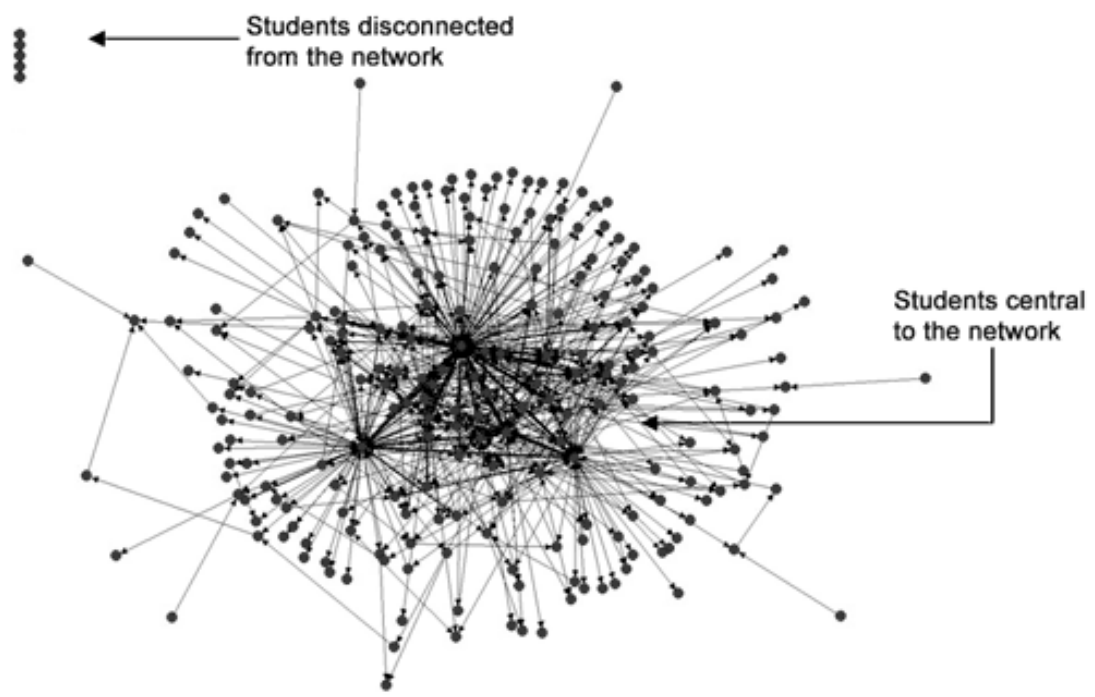

Figure 6: Social Network Analysis diagram based on interactions on discussion forums allows seeing disconnected and key network students (from Dawson, 2009). Nodes in this node-link diagram represent students, where the edges represent relationships between students.

Similarly, new hardware provides affordances for subtle visual ambient feedback: a nice example is Reflect (Bachour, Kaplan, \& Dillembourg, 2008), where an array of LEDs is used to give feedback on the participation of learners around a table that monitors interaction through embedded microphones. Making the group dynamics accessible and open to interpretation can motivate participants to reflect on their contributions, in a learning setting as well as in other contexts (Gilbert, \& Karahalios, 2009; Viterbo, Barsotti, \& Vande Moere, 2011).

The third example (see Figure 7) illustrates how contributions to an open source software project are visualized: a similar approach could help to understand contributions to Massive Open Online Courses (MOOC's) (Fini, 2009). This kind of social visualization for learning has only been studied on limited scale so far: the Comtella project researched this approach in the context of shared papers, not only for research but also for learning 
Klerkx, Verbert \& Duval

(Vassileva, 2008). Findings showed that users that made more original contributions, consulted this visualization more often then users that made less contributions. However, the quality of the contributions itself deteriorated when the number of contributions increased. Ways to game and exaggerate contributions to gain higher status and visibility were quickly found by several users. In such a context, a visualization that shows subtle cues on the quality of participation can help (Erickson, 2007). Visual social cues including dynamic rewards, indications of reputation and virtual currencies for rating contributions by others, were therefore included as well.

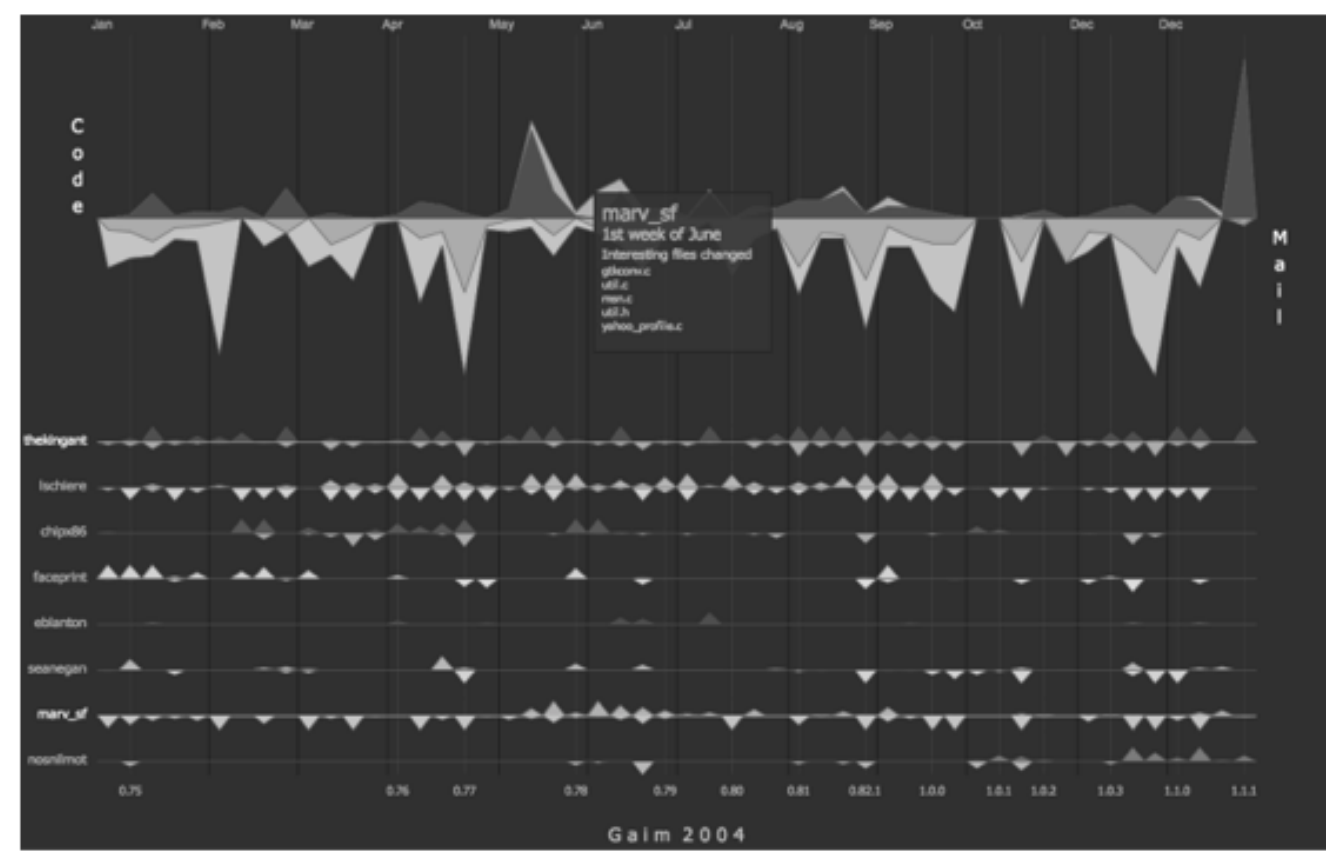

Figure 7: Visualizing code share contributions over time (x-axis). The visualization contains a combined view of all users (top) and a detailed view per user (bottom). Adapted from Gilbert and Karahalios (2007).

Other existing applications focus on visualization of activities within a team in order to increase collaboration among team members. For example, the Activity Radar (Kay, et al., 2006) consists of a circle, representing the range of participation, and colored dots 
that represent team members (see Figure 8). A dot is placed on a radius and moves to the center as the level of participation increases. The inner, darker perimeter represents the average level of participation. In addition to supporting awareness and self-reflection for both teachers and learners, the visualization is targeted to increase collaboration among learners in group work.
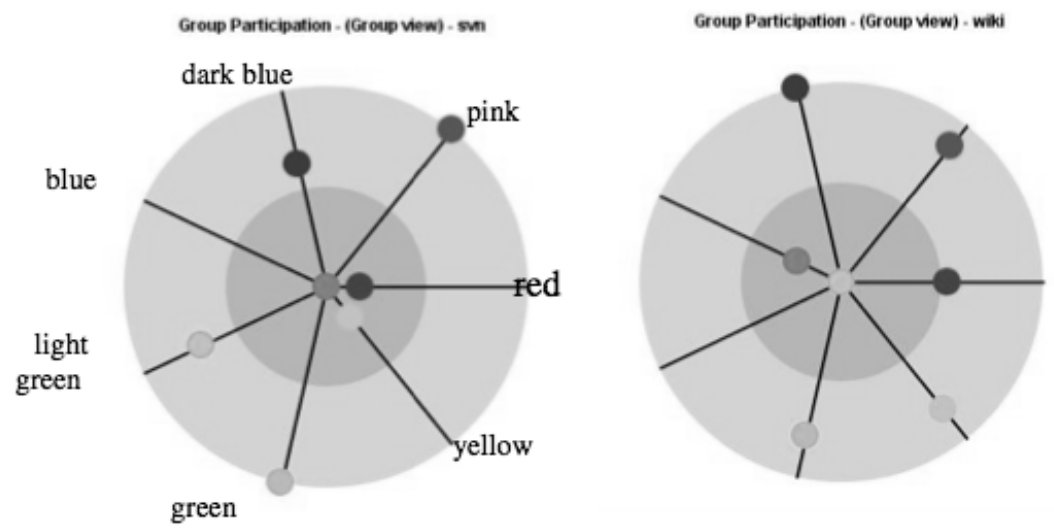

Figure 8: Dots in the Activity Radar represents the average level of participation in group work (from Kay et al., 2006).

\section{Discussion}

The use of visualization techniques for enhancing collaborative learning is not limited to the examples above. For more examples readers should refer to the work of Soller and Jermann (2005). The effect on learning effectiveness of many of these techniques is still unclear. As an example, Janssen, et al. (2007) reported the effect of visualizing participation in CSCL for learners in a secondary school in the Netherlands. Basically, both the number and size of intra-group messages were visualized for groups of students working together on an inquiry task. Those with access to the visualization used it intensively and engaged in more coordination activities. However, this did not lead to increased quality of the group products. Further research is needed to assess the added value of visual approaches in terms of effectiveness, efficiency or other criteria that 
Klerkx, Verbert \& Duval

pertain to learning. Outside of a CSCL context, the social context and more specifically, social awareness, may also help a learner to situate his efforts and performance with respect to his peers - this is the topic of the next section.

\section{(Self-)Reflection about the learning process}

Researchers are focusing increasingly on the need for better measurement, tracking, analysis and visualization of data about learners while they are learning. The field of "learning analytics" therefore focuses on the tracking and analysis of activities to help understand and optimize learning and the environments and contexts in which it occurs (Blakelock \& Smith, 2006). Data on user activities is often captured and analyzed as a basis for researching learning processes (Alavi et al., 2009). Visualization of such data is a key for gaining insight into learning effects achieved and potential impact of technologies on learning. In addition, the application of visualization techniques has been researched to support self-reflection and awareness and collaboration among learners or teachers (Soller \& Jermann, 2005). It offers both learners and teachers a feedback or evaluation loop for what is working and not working in the learning process, which materials are used and how many times, how active the students are, and the like.

Several tools have been developed to visualize monitoring data as a basis for selfreflection and awareness. Hardy et al. (2008) developed a tool that can visualize in the form of a directed graph the path taken through a course session, including all pages, online accesses and pop-up windows (see Figure 9A). In addition, the length of time on each page is visualized. These visualizations are --in essence -- directed node-link graphs, with nodes representing pages and edges representing access between pages (see Figure 9B). The size of a circle represents the total time spent on a page. The time of page accesses is also visualized, with a vertical line representing a page access. Lines that are 
close together show rapid access, while lines further apart show less frequent access times (see Figure 9C). The main added value of this tool is that it enables researchers to gain insight into the complex spatial and temporal routes taken by students through the material. Students or teachers did not use the visualizations themselves. Hence, no conclusions about the added value of this tool in the learning process can be drawn.

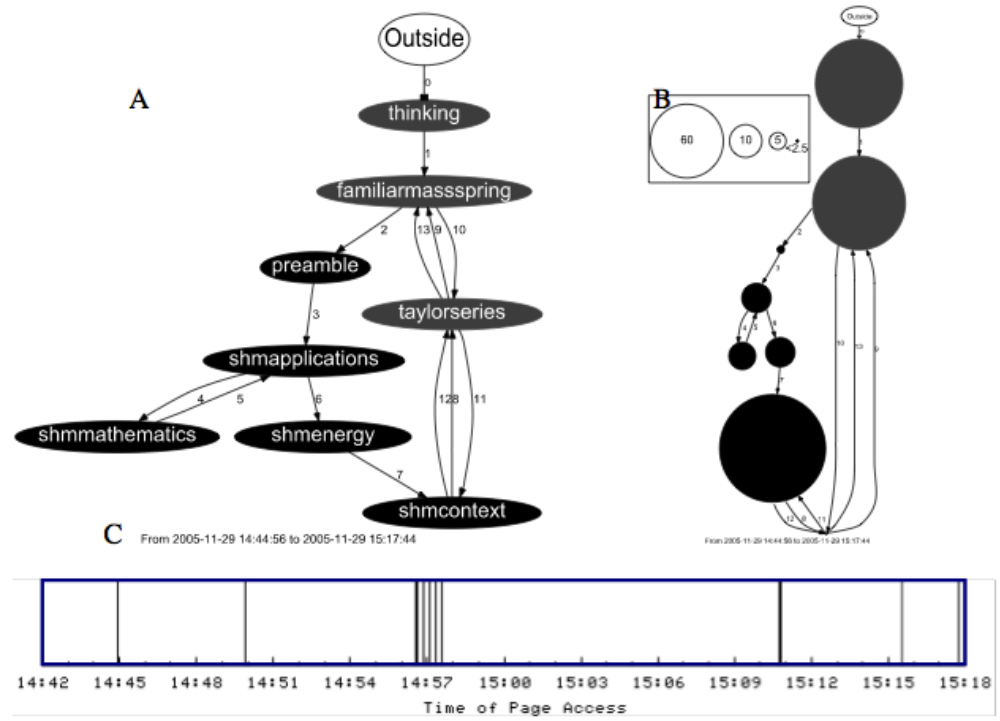

Figure 9: Path taken (A), time spending (B), and access time (C) visualizations (from Hardy et al., 2008).

Mazza and Milani (2005) presented the GISMO system that also visualizes accesses to a course and its resources. Among others, the application relies on a simple matrix visualization of student names (on the $\mathrm{Y}$-axis) and resource names (on the $\mathrm{X}$-axis) to represent resource accesses. The color of cells in this matrix range from light blue to dark blue according to the number of times a learner accessed a resource. Besides this, time can be chosen on the $\mathrm{X}$-axis, which enables users to gain insights into the sequence of resources that were used. However, instead of estimated time, the number of resource 
Klerkx, Verbert \& Duval

accesses is used. Like the first approach, the Student Activity Meter (SAM) (Govaerts, et al., 2010) is focused on time estimates as a basis to support awareness and self-reflection. Figure 10 shows some of the visualizations that SAM provides:

- The line chart (vis. A in Figure 10) shows a line for every student, connecting all the timestamps when she was working with the cumulative amount of time spent. The inclination of the line shows the effort of the student. A steep line means an intensive working period. A flat line shows inactivity.

- Statistics of global time spent and document use are shown in box 2 in Figure 10. Next to the actual numbers, a graphical view is presented with color-coding of the minimum, maximum and average time spent and documents used, to give the user a visual comparison.

- The recommendation pane in box 3 allows navigating through the most used and the most time spent on resources.

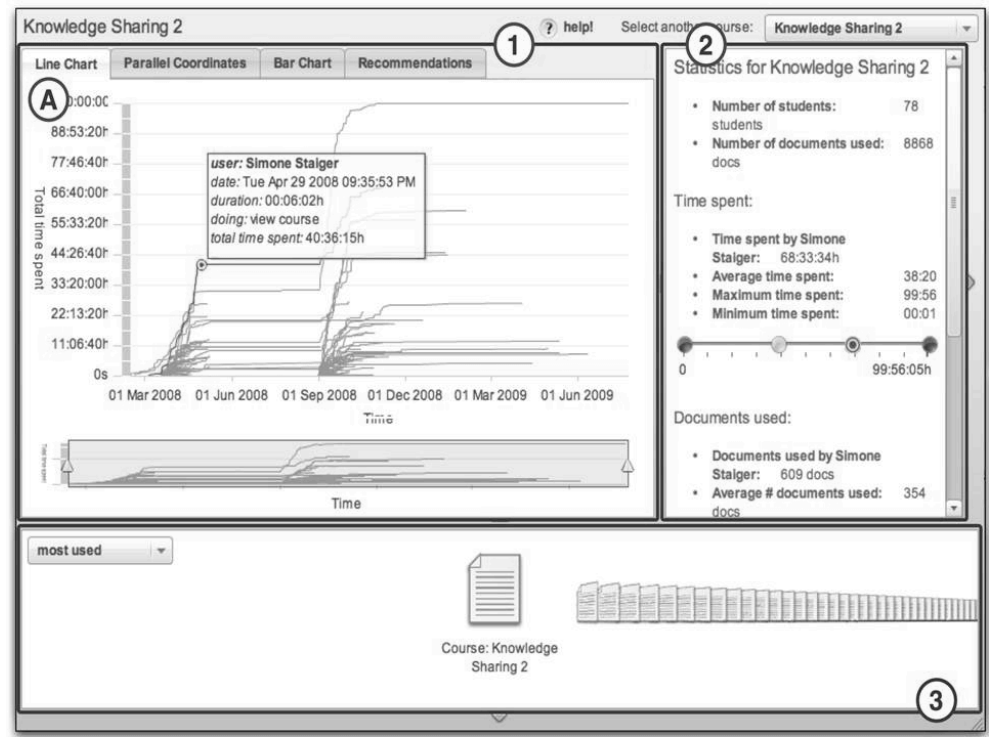

Figure 10: Student Activity Meter (SAM) (from Govaerts, et al., 2010). 
Through a usability test with interviews and the think aloud protocol, the authors found out that SAM is easy to work with the tool the first time (Govaerts, et al., 2010). The numbers of errors were low and no unrecoverable errors were encountered. A System Usability Scale (SUS) test for measuring user satisfaction achieved an average score of $73 \%$, which puts the tool on par with mainstream software tools. Based on these findings, the authors concluded that such visualizations appear to be useful for both teachers and learners during the learning process.

Visualizing knowledge levels of students has been explored in ViSMod (Zapata-Rivera \& Greer, 2002), the UM toolkit (Kay, 1995) and KERMIT (Hartley \& Mitrovic, 2002). VisMod uses concept maps to render a Bayesian learner model. The UM toolkit uses different types of geometric forms to represent known and unknown concepts. KERMIT uses histograms to represent knowledge levels of learners. The visualizations of these systems provide a representation of a learner model, which is built automatically using artificial intelligence techniques (Mazza \& Milani, 2005). As these inferences are often challenging, many other visualization tools rely on self-assessment tools to capture the current knowledge level of a learner (Nussbaumer, 2008).

\section{Discussion}

The tools presented in this section visualize different indicators aimed at fostering awareness and reflection about learning processes or changes in them. These indicators include resource access, time spent on learning activities, and knowledge level indicators. Many of the tools enable learners to compare and contrast their data with peers. The visualization tools are also often intended to increase teacher awareness of how learners spend their time and what resources they use, and to provide teachers with feedback on well they designed their own courses. Whereas the tools presented in this section 
Klerkx, Verbert \& Duval

illustrate the potential of visualization techniques to support these objectives, the effect on learning outcomes from many of these techniques is unclear. Evaluation studies have so far only assessed the usability and usefulness in controlled experiments. The perceived usefulness by both teachers and learners is in all cases high. However, real-life case studies that evaluate the impact of visualization techniques for learning analytics on learning effectiveness and efficiency have not yet been carried out.

\section{Designing environments to facilitate learning processes}

The goal of instructional design is to create instructional learning experiences that make the acquisition of knowledge and skill more efficient, effective, and appealing (Merrill et al., 1996). The ADDIE process model distinguishes the main stages of the instructional design process: Analysis, Design, Development, Implementation, and Evaluation (Molenda, 2003). The outcome of each stage feeds into the next stage. One accepted improvement to this model is the use of rapid prototyping that includes continuous feedback in the instructional design process. In this section, we aim to show how visualization techniques can facilitate the analysis and design stages of the instructional design process.

During the analysis phase of instructional design, one tries to understand the audience needs, constraints, existing knowledge, skills, the desired outcome of the course, the learner environment, the timeline for the learning experience, etc. This information is then fed into a design stage where learning objectives, methods for presenting relevant information, assessment criteria, and the like are specified. A so-called "learning design" captures this kind of information in an explicit way and is therefore typically defined as the application of learning design knowledge when developing a concrete unit of learning, e.g. a course, a lesson, a curriculum, or a learning event (Koper \& Tattersall, 
2005). A popular formal language to describe such learning designs is the IMS Learning Design (LD) specification, which provides elements such as roles (for instance students or educators), activities (for instance a discussion about a topic), and environments (for instance a learning management system), to describe designs of the teaching and learning process in a formal way. IMS LD is sometimes considered hard to understand and it would therefore take considerable effort from teachers to apply it in concrete situations (Griffths \& Blat, 2005; Neumann \& Oberhuemer, 2009).

Visualization can facilitate the analysis and design stages by providing visual support. OpenGLM (Neumann \& Oberhuemer, 2009), the London Pedagogy Planner (San Diego et al., 2008), CompendiumLD "http://compendiumld.open.ac.uk/“, LAMS (Dalziel, 2003) are only some examples of tools that support lecturers in analyzing, designing and sharing learning designs in a visual way. Several visualization techniques are used in these tools. The London Pedagogy Planner (San Diego et al., 2008) includes a spreadsheet-like overview where lecturers distribute the available learner time over different cognitive activities, as well as a schedule of topics and a visualization of how they related to learning outcomes (see Figure 11). The idea is to visually support teachers through interactive, adaptive, reflective, discursive and collaborative learning designs.

CompendiumLD includes mind maps, concept maps, web maps and argumentation maps such as the one that were discussed before (see Figure 5). Those maps are in fact nodelink diagrams where nodes can represent typical LD elements such as activities, roles and environments and links can represent flows between activities. Similar maps are used in the OpenGLM tool (see Figure 12). 
Klerkx, Verbert \& Duval

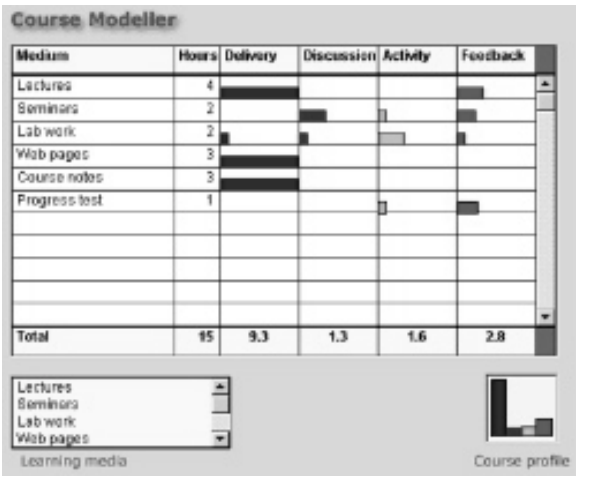

Figure 11: The London Pedagogy Planner: distributing learner time over learning activities such as discussion, lab work, lectures, etc. (from San Diego et al., 2008)

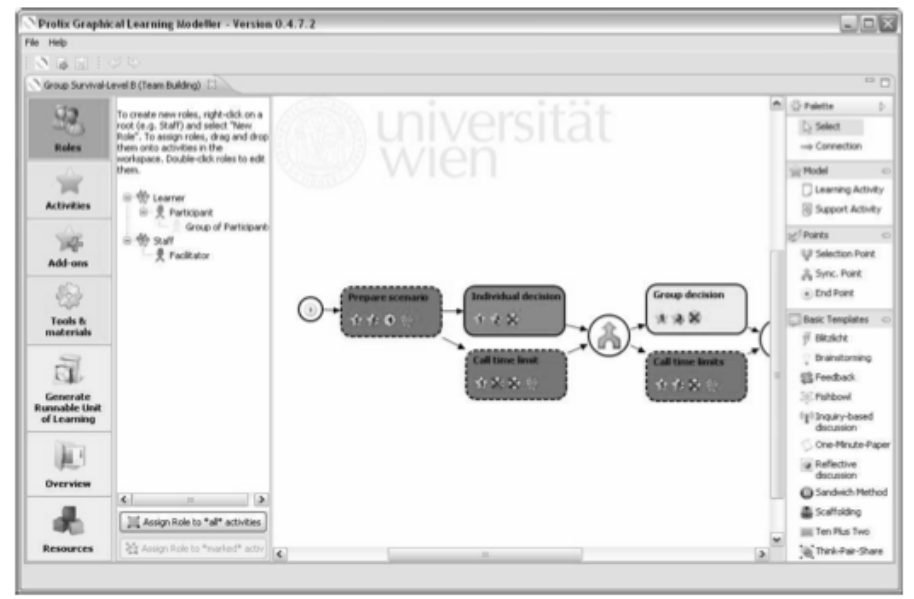

Figure 12: The Open Graphical Learning Modeler: visualization helps to offload information from working memories of teachers (from Neumann \& Oberheumer, 2009).

The middle part of the user interface enables the user to visually create a sequence of activities. Connections between activities can be drawn in that area by making use of the design palette (upper right corner). The graphic design is interpreted by the GLM after which the corresponding manifest file of the IMS LD package is automatically generated (Neumann \& Oberhuemer, 2009). The main added value of this tool is that it enables its users to offload information from their cognitive working memories. The authors 
performed a user evaluation with a test population of 21 users to validate if the graphical editor actually reaches its goal of removing technical barriers that instructional design in general and IMS LD in particular presents. The test participants successfully created complete learning designs that could be exported as units of learning and reported good usability in their feedback. For an overview of a similar tool, we refer readers to the work of Dodero, Val, and Torres (2010) as well.

\section{Discussion}

The power of the visualization techniques for the analysis and design phase comes from the fact that it is possible to have a far more complex concept structure, such as an instructional design, represented externally in a visual display than can be held in visual and verbal working memories of users while designing their courses (Ware, 2004). Apart from this generic design support that visualization techniques offer, these tools also hide some of the technical complexities in standards such as IMS LD - a specification that has not yet been widely adopted since its inception (Derntl, Neumann, Griffiths, \& Oberhuemer, 2010). In that sense, we can say that the visualization techniques can facilitate the design stage of the learning process.

\section{Conclusions}

As the field of Visualization is becoming more mature, visualization techniques are moving out of research laboratories (Plaisant, 2004) into application domains such as elearning. There are a multitude of educators and learners who are interested in data on educational resources, learning processes, student activities, social learning networks, and the like, whose analyses can benefit from the field of visualization. These techniques make it possible for learners, educators, researchers, and the general public to obtain insight in these data in an efficient and effective way, thanks to the unique capabilities of 
Klerkx, Verbert \& Duval

the human visual system (Van Wijk, J. J., 2005) that allows us to detect interesting features and patterns in a short time. The role of visualization in an educational context is potentially much more versatile than simply increasing information awareness: as has been shown in this chapter, visualization applied to resource searching, collaboration, reflection, and instructional design has the unique potential to help shape the learning process and encourage reflection on its progress and impact. Examples in this chapter have shown how these techniques can enhance several activities of the learning process. However, we do want to point to a lack of thorough experiments in real-life settings to assess usefulness of these techniques during the learning process. One reason for this might be the difficulty of evaluating visualization applications and more specifically the difficulty to understand and measure the impact of visualization in learning (Fekete \& Van Wijk, 2008). We can thus conclude that visualization techniques are becoming more common tools in the learning process but further research is needed to assess the added value of these visual approaches in terms of effectiveness, efficiency or other criteria that pertain to learning, including --for instance-- aesthetical appeal and fun. 
Chapter \#: Enhancing Learning with Visualization Techniques

\section{References}

Adnan, W., Daud, N., \& Noor, N. (2008). Expressive Information Visualization Taxonomy for Decision Support Environment. In Proceedings of Third International Conference on Convergence and Hybrid Information Technology (88-93)

Ahn, J.-W., \& Brusilovsky, P. (2009). Adaptive visualization of search results: Bringing user models to visual analytics. Information Visualization, 8(3), 167-179.

Alavi, H. S., Dillenbourg, P., \& Kaplan, Frederic. (2009). Distributed Awareness for Class Orchestration. Learning in the Synergy of Multiple Disciplines, Lecture Notes in Computer Science, 5794, 211-225). Berlin / Heidelberg: Springer.

Arcavi, A. (2003). The role of visual representations in the learning of mathematics. Educational Studies in Mathematics, 52, 215-241.

Bachour, K., Kaplan, F., \& Dillembourg, P. (2008). Reflect : An Interactive Table for Regulating Face-to-Face Collaborative Learning, In Times of Convergence. Technologies Across Learning Contexts, Lecture Notes in Computer Science, 5192, 39-48. Berlin, Heidelberg: Springer.

Blakelock, J., \& Smith, T. (2006). Distance learning: From multiple snapshots, a composite portrait. Computers and Composition, 23(1), 139-161.

Braak, S.W. van den, Oostendorp, H. van, Prakken, H. \& Vreeswijk, G.A.W. (2006). A critical review of argument visualization tools: Do users become better reasoners? In F. Grasso, R. Kibble \& C. Reed (Eds.), Workshop Notes of the ECAI-06 Workshop on Computational Models of Natural Argument, (67-75).

Bouzeghoub, A., Buffat, M., Lopes Gançarski, A., Lecocq, C., Benjemaa, A., Selmi, M., et al. (2009). Search and Composition of Learning Objects in a Visual Environment. Learning in the Synergy of Multiple Disciplines, Lecture Notes in Computer Science, 5794, 763-768. Berlin / Heidelberg: Springer

Burkhard, R. A., \& Meier, M. (2005). Tube Map Visualization: Evaluation of a Novel Knowledge Visualization Application for the Transfer of Knowledge in Long-Term Projects. Journal of Universal Computer Science, 11(4), 473-494. 
Klerkx, Verbert \& Duval

* Card, S. K., Mackinlay, J. D., \& Shneiderman, B. (1999). Readings in Information Visualization: Using vision to think (pp. 579-581). San Francisco, Morgan Kaufmann Publishers Inc.

Carr. C. S. (2003) Visualizing Argumentation: Software Tools for Collaborative and Educational Sense-Making, Using computer supported argument visualization to teach legal argumentation, 75-96. Springer-Verlag.

Chi, E. H. (2000). A taxonomy of visualization techniques using the data state reference model. In Proceedings of the IEEE Symposium on Information Visualization, pp 69-75.

Clarkson, E., Desai, K., \& Foley, J. (2009). ResultMaps: visualization for search interfaces. IEEE transactions on visualization and computer graphics, 15(6), 1057-64.

Dalziel, J., (2003). Implementing Learning Design: The Learning Activity Management System (LAMS), In Proceedings of the ASCILITE 2003 Conference, Adelaide

Dawson, S. (2009). Seeing' the learning community: An exploration of the development of a resource for monitoring online student networking. British Journal of Educational Technology, 41(5), 736-752

Derntl, M., Neumann, S., Griffiths, D., \& Oberhuemer, P. (2010). Investigating teachers' understanding of IMS learning design: yes they can!, In Proceedings of the 5th European conference on Technology enhanced learning conference on Sustaining TEL: from innovation to learning and practice, 62-77, Berlin Heidelberg: Springer-Verlag

Dicheva, D., \& Dichev, C. (2006). TM4L: Creating and browsing educational topic maps. British Journal of Educational Technology, 37(3), 391-404.

Dillenbourg, P. (2002) "Over-scripting CSCL: The risks of blending collaborative learning with instructional design" In: (Kirschner, P.A. eds.,) Three Worlds of CSCL. Can We Support CSCL, Open Universiteit Nederland, Heerlen, pp 61-91

Dillenbourg, P., Järvelä, S., \& Fischer, F. (2009). The Evolution of Research on ComputerSupported Collaborative Learning: From Design to Orchestration, In (N. Balacheff, S. Ludvigsen, T. Jong, A. Lazonder, \& S. Barnes, Eds.) Technology-Enhanced Learning, I, 319, Dordrecht: Springer Netherlands.

Dodero, J. M., Val, Á. M. del, \& Torres, J. (2010). An extensible approach to visually editing adaptive learning activities and designs based on services. Journal of Visual Languages \& Computing, 21(6), 332-346. 
Chapter \#: Enhancing Learning with Visualization Techniques

Duval, E., \& Hodgins, W. (2003). A LOM Research Agenda. In Hencsey, G., White, B., Chen, Y., Kovacs, L., and Lawrence, S., (editors), Proceedings of the 12th International World Wide Web Conference, 659-667, New York: ACM Press.

Eck, D. J. (1995). The most complex machine: A survey of computers and computing (p. 445). A K Peters (Wellesley, Mass.).

Ellis, G., \& Dix, A. (2007). A Taxonomy of Clutter Reduction for Information Visualisation. IEEE Transactions on Visualization and Computer Graphics, 13(6), 1216-1223. Piscataway, NJ, USA: IEEE Educational Activities Department.

Elmqvist, N., Stasko, J., \& Tsigas, P. (2008). DataMeadow: A Visual Canvas for Analysis of Large-Scale Multivariate Data. Information Visualization, 7(1), 18-33.

Elmqvist, N., \& Fekete, J. (2010). Hierarchical Aggregation for Information Visualization: Overview, Techniques, and Design Guidelines. IEEE Transactions on Visualization and Computer Graphics, 16(3), 439-454.

Erickson, T. (2007). "Social" systems: designing digital systems that support social intelligence. AI \& SOCIETY, 23(2), 147-166.

* Fekete, J-D., Van Wijk, J. J., Stasko, J. T, \& North, C. (2008). The Value of Information Visualization. Information Visualization, 1-18.

* Few, S. (2009). Now you see it: simple visualization techniques for quantitative analysis. Oakland, CA: Analytics Press.

Fini, A. (2009, February 11). The Technological Dimension of a Massive Open Online Course: The Case of the CCK08 Course Tools. In The International Review of Research in Open and Distance Learning. 10(5).

Furnas, G. W. (1999). The Fisheye view: a new look at structured files. Readings in information visualization: using vision to think, 312-330. San Francisco, CA, USA: Morgan Kaufmann Publishers Inc.

Gilbert, E., \& Karahalios, K. (2009). Using Social Visualization to Motivate Social Production. IEEE Transactions on Multimedia, 11(3), 413-421.

Govaerts, S., Verbert, K., Klerkx, J., \& Duval, E. (2010). Visualizing Activities for Self-reflection and Awareness. Proceedings of the 9th international conference on Webbased Learning (110). Springer. 
Klerkx, Verbert \& Duval

Govaerts, S., Verbert, K., Pardo, A., \& Duval, E. (2012). The Student Activity Meter for Awareness and Self-Reflection. Proceedings of the 2012 annual conference extended abstracts on Human factors in computing systems (CHI EA '12). 16 pages, ACM Press.

Griffths, D., \& Blat, J. (2005). The Role of Teachers in Editing and Authoring Units of Learning Using IMS Learning Design. Advanced Technology for Learning, 2(4).

Hardy, J., Bates, S., Hill, J., \& Antonioletti, M. (2008). Tracking and Visualisation of Student Use of Online Learning Materials in a Large Undergraduate Course. In H. Leung, F. Li, R. Lau, \& Q. Li (Eds.), Advances in Web Based Learning (ICWL 2007) (Vol. 4823, pp. 464-474). Springer.

Hartley, D., \& Mitrovic, A. (2002). Supporting Learning by Opening the Student Model. Intelligent Tutoring Systems (Vol. 2363, p. 185-191). Springer.

Hearst, M. (2009). Search user interfaces. Cambridge: Cambridge University Press.

Heer, J., \& boyd, D. (2005). Vizster: Visualizing Online Social Networks. In IEEE Information Visualization, 32-39.

Heer, J., \& Shneiderman, B. (2012). Interactive Dynamics for Visual Analysis. Queue, 10(2), 26 pages, http://doi.acm.org/10.1145/2133416.2146416

Herman, I., Melancon, G., \& Marshall, M. S. (2000). Graph visualization and navigation in information visualization: A survey. Visualization and Computer Graphics, IEEE Transactions on, 6(1), 24-43

Hundhausen, C. D., Douglas, S. A., \& Stasko, J.T. (2002). A meta-study of algorithm visualization effectiveness. Journal of Visual Languages \& Computing, 13(3), 259-290. Elsevier.

Inselberg, A. (1985). The plane with parallel coordinates. The Visual Computer, 1(4), 69-91

Kanuka, H., \& Anderson, T. (1999). Using constructivism in technology-mediated learning: Constructing order out of the chaos in the literature. Radical Pedagogy, 1(2).

Kay, J. (1995). The UM toolkit for cooperative user modelling. User Modeling and User Adapted Interaction, 4(3), 149-196. 
Chapter \#: Enhancing Learning with Visualization Techniques

Kay, J., Maisonneuve, N., Yacef, K., \& Reimann, P. (2006). The Big Five and Visualisations of Team Work Activity. In (M. Ikeda, K. D. Ashley, \& T.-W. Chan, Eds.) Intelligent tutoring systems, 4053(4053), 197-206. Springer.

Keim, D. A. (2000). Designing pixel-oriented visualization techniques: theory and applications. IEEE Transactions on Visualization and Computer Graphics, 6(1), 59-78.

Keim, D. A. (2002). Information visualization and visual data mining. IEEE Transactions on Visualization and Computer Graphics, 8(1), 1-8. IEEE Educational Activities Department.

Keim, D., Andrienko, G., Fekete, J.-D., Görg, C., Kohlhammer, J., \& Melançon, G. (2008). Visual Analytics: Definition, Process, and Challenges. In A. Kerren, J. Stasko, J.-D. Fekete, \& C. North (Eds.), Information Visualization, 154-175. Berlin / Heidelberg: Springer.

Kirschner, P.A., Simon, J., Buckingham, S., \& Chad, S. (2003). Visualizing Argumentation: Software Tools for Collaborative and Educational Sense-Making. London: Springer-Verlag

Klamma, R., Spaniol, M., Cao, Y., \& Jarke, M. (2006). Pattern-Based Cross Media Social Network Analysis for Technology Enhanced Learning in Europe. In W. Nejdl \& K. Tochtermann (Eds.), Innovative Approaches for Learning and Knowledge Sharing, 4227, 242-256. Berlin / Heidelberg: Springer

Klerkx, J., Duval, Erik, \& Meire, M. (2004). Using information visualization for accessing learning object repositories. In E. Banissi, K. Börner, C. Chen, M. Dastbaz, G. Clapworthy, A. Faiola, et al. (Eds.), Information Visualization (IV04), 465-470/

Kobsa, A. (2004). User Experiments with Tree Visualization Systems. IEEE Symposium on Information Visualization, 9-16.

Koper, R., \& Tattersall, C. (2005). An Introduction to Learning Design - Learning Design, Berlin Heidelberg: Springer.

Lalingkar, A., \& Ramani, S. (2010). A Topic Map-based System for Identifying Relevant Learning Objects. World Conference on Educational Multimedia, Hypermedia and Telecommunications 2010, 1044 - 1053.

Lamping, J., \& Rao, R. (1996). The Hyperbolic Browser: A Focus+Context Technique for Visualizing Large Hierarchies. Journal of Visual Languages \& Computing, 7(1), 33-55.

Lee, C.-S. (2007). Ontological Sharing, Granular Visualization and Reusability of Learning Objects. Learning Objects and instructional design, 171-196. 
Klerkx, Verbert \& Duval

Marchionini, G. (2006). Exploratory search: from finding to understanding. Communications of ACM , 49(4), 41-46.

Mazza, R., \& Milani, C. (2005). Exploring Usage Analysis in Learning Systems: Gaining Insights From Visualisations. Intelligence in education, (July), 65. In AIED Workshops (AIED’05)

Merrill, M. D., Drake, L., Lacy, M. J., \& Pratt, J. (1996). Reclaiming Instructional Design. Educational Technology, 36(5), 5-7.

Molenda, M. (2003). In search of the elusive ADDIE model. Performance Improvement, 42(5), 34-36.

Morville, P. (2005). Ambient Findability. O’Reilly Media, Inc.

Naps, T. L., Fleischer, R., Mcnally, M., Rößling, G., Hundhausen, C., Rodger, S., et al. (2003). Exploring the role of visualization and engagement in computer science education. $A C M$ SIGCSE Bulletin.

Neumann, S., \& Oberhuemer, P. (2009). User Evaluation of a Graphical Modeling Tool for IMS Learning Design. In M. Spaniol, Q. Li, R. Klamma, \& R. W. H. Lau (Eds.), Advances in Web Based Learning (Vol. 5686, pp. 287-296). Berlin Heidelberg: Springer

Nowell, L., Havre, S., Hetzler, E., \& Whitney, P. (2002). Themeriver: Visualizing Thematic Changes in Large Document Collections. IEEE Transactions on Visualization and Computer Graphics, 8(1), 9-20.

Nussbaumer, A. (2005). Integrating Four Graph-Based Hierachy Browsers into the Hierarchical Visualisation System (HVS). Graz University of Technology, Masters Thesis.

Nussbaumer, A. (2008). Supporting Self-Reflection through Presenting Visual Feedback of Adaptive Assessment and Self-Evaluation Tools. Proceedings of the 11th International Conference on Interactive Computeraided Learning ICL 2008 (Vol. 1)

* Presmeg, N. (2006). Research on visualization in learning and teaching mathematics. In $A$. Gutiérrez \& P. Boero (Eds.), Handbook of research on the psychology of mathematics education, 205-235. Rotterdam: Sense Publishers.

Pryke, A., Mostaghim, S., \& Nazemi, A. (2007). Heatmap Visualization of Population Based Multi Objective Algorithms. In S. Obayashi, K. Deb, C. Poloni, T. Hiroyasu, \& T. Murata (Eds.), Evolutionary Multi-Criterion Optimization (Vol. 4403, pp. 361-375) 
Chapter \#: Enhancing Learning with Visualization Techniques

Reigeluth, C. M. (1999). Instructional-design Theories and Models: A new paradigm of instructional theory (Vol.2). Lawrence Erlbaum Associates.

Reinhardt, W., Moi, M., \& Varlemann, T. (2009). Artefact-Actor-Networks as tie between Social Networks and Artefact Networks. Proceedings of the 5th International ICST Conference on Collaborative Computing: Networking, Applications and Worksharing (CollaborateCom 2009), 1-10.

Rivadeneira, W., \& Bederson, B B. (2003). A Study of Search Result Clustering Interfaces: Comparing Textual and Zoomable User Interfaces. Studies, 21, 5.

Santos, R. D., Gros, P., Abel, P., Loisel, D., Trichaud, N., \& Paris, J. P. (2000). Experiments in Information Visualization Using 3D Metaphoric Worlds. Proceedings of WETICE00: Enabling Technologies: Infrastructure for Collaborative Enterprises, 51-58.

San Diego, J., Laurillard, D., Boyle, T., Bradley, C., Ljubojevic, D., Neumann, T., et al. (2008). Towards a user-oriented analytical approach to learning design. Alt-J, 16(1), 15-29.

Sha, L., Teplovs, C., \& Aalst, J. van. (2010). A visualization of group cognition: semantic network analysis of a CSCL community. Proceedings of the 9th International Conference of the Learning Sciences, 1, 929-936.

Shaffer, C. A., Cooper, M., \& Edwards, S. H. (2007). Algorithm visualization. ACM SIGCSE Bulletin, 39(1), 150.

Schank, P. \& Ranney, M. (1995). Improved reasoning with Convince Me. In CHI '95: Conference Companion on Human Factors in computing Systems, pp. 276-277, New York, NY. ACM Press.

Shneiderman, B., \& Johnson, B. (1991). Tree-Maps: A Space Filling Approach to the Visualization of Hierarchical Information Structures. In Proceedings of VIS91: Second Conference on Visualization, 284-291.

* Shneiderman, B. (1996). The Eyes Have It: A Task by Data Type Taxonomy for Information Visualizations. In Proceedings of the 1996 IEEE Symposium on Visual Languages, 336343. Washington, DC, USA: IEEE Computer Society.

* Shneiderman, B., \& Bederson, B. (2003). The Craft of Information Visualization: Readings and Reflections. Morgan Kaufmann Publishers Inc. 
Klerkx, Verbert \& Duval

Sicilia, M.-Á., Lytras, M. D., Sánchez-Alonso, S., García-Barriocanal, E., \& Zapata-Ros, M. (2010). Modeling instructional-design theories with ontologies: Using methods to check, generate and search learning designs. Computers in Human Behavior, 27(4), 1389-1398.

Soller, A., \& Jermann, P. (2005). From Mirroring to Guiding: A Review of State of the Art Technology for Supporting Collaborative Learning. International Journal on Artificial Intelligence Ed, 15(4), 261-290. IOS Press.

Stahl, G., Koschmann, T., \& Suthers, D. (2006). Computer-supported collaborative learning: A historical perspective. In R. K. Sawyer (Ed.), Cambridge Handbook of the learning sciences (pp. 406-427). Cambridge: Cambridge University Press

Stefaner, M., Urban, T., \& Marc, S. (2008). Elastic Lists for Facet Browsing and Resource Analysis in the Enterprise. In Proceedings of DEXA08: Nineteenth International Conference on Database and Expert Systems Applications, 397-401.

* Steele, J., \& Iliinsky, N. (2010). Beautiful visualization (p. 397). O’Reilly Media, Inc

Sumner, T., Ahmad, F., Bhushan, S., Gu, Q., Molina, F., Willard, S., et al. (2005). Linking learning goals and educational resources through interactive concept map visualizations. International Journal on Digital Libraries, 5(1), 18-24.

Suthers, D., Weiner, A., Connelly, J., \& Paolucci., M. (1995). Belvedere: Engaging students in critical discussion of science and public policy issues. In AI-Ed 95, the 7th World Conference on Artificial Intelligence in Education, pp. 266-273.

Ternier, S, Verbert, K, Parra, G., Vandeputte, B., Klerkx, K., Duval, E, (2009). The ARIADNE infrastructure for managing and storing metadata. IEEE Internet Computing, 13(4), pp. 1825.

van Gelder, T. J. (2002). 'Argument mapping with Reason!Able', The American Philosophical Association Newsletter on Philosophy and Computers, 85-90.

Vande Moere, A., \& Purchase, H. C. (2011). On the role of design in information visualization. Information Visualization, 10(4).

Van Wijk, J. J., \& Van Seelow, E. R. (1999). Cluster and Calendar Based Visualization of Time Series Data. Proceedings of the IEEE Symposium on Information Visualization, 4-9.

Van Wijk, J. J. (2005). The Value of Visualization. VIS 05. IEEE Visualization, 79-86. IEEE 
Chapter \#: Enhancing Learning with Visualization Techniques

Vassileva, J. (2008). Toward Social Learning Environments. IEEE Transactions on Learning Technologies, 1(4), 199-214.

Viterbo, P. B, Barsotti, V., \& Vande Moere, A., (2011). Situated \& Social Feedback in the City. Proceedings of CHI2011. Vancouver, Canada: ACM Press.

Wang, Y., Teoh, S. T., \& Ma, K.-L. (2006). Evaluating the Effectiveness of Tree Visualization Systems for Knowledge Discovery. Proceedings of Eurographics Visualization Symposium, $(67-74)$.

* Ware, C. (2004). Information Visualization: Perception for Design. San Francisco, CA, USA: Morgan Kaufmann Publishers Inc.

Willett, W., Heer, Jeffrey, \& Agrawala, M. (2007). Scented Widgets: Improving Navigation Cues with Embedded Visualizations. In IEEE Transactions on Visualization and Computer Graphics, 13(6), 1129-1136.

Woolner, P. (2004). A comparison of a visual-spatial approach and a verbal approach to teaching mathematics. In M. J. Høines \& A. B. Fuglestad (Eds.), Proceedings of the $28^{\text {th }} P M E$ International Conference, 4, 449-456

Yi, J. S., Elmqvist, N., \& Lee, S. (2010). TimeMatrix: Analyzing Temporal Social Networks Using Interactive Matrix-Based Visualizations. International Journal of Human-Computer Interaction, 26(11\&12), 1031-1051

Zapata-Rivera, D., \& Greer, J. E. (2002). Exploring Various Guidance Mechanisms to Support Interaction with Inspectable Learner Models. Intelligent Tutoring Systems 6th International Conference, 442-452.

\section{Acknowledgements}

Katrien Verbert is a Postdoctoral Fellow of the Research Foundation Flanders - FWO.

Furthermore, many thanks to all the people who responded on our calls for input through

Facebook and Twitter!

\section{Author Information}

Institutional affiliation: Katholieke Universiteit Leuven 
Klerkx, Verbert \& Duval

Institutional address: Celestijnenlaan 200A, 3000 Leuven, Belgium

Complete mailing address:

Departement Computerwetenschappen

K.U.Leuven

Celestijnenlaan 200A - bus 2402

3001 Heverlee

Belgium

Telephone number: $++32(0) 16 / 32.77 .00$

Fax number (optional): $++32(0) 16 / 32.79 .96$

Email address: \{Joris.klerkx, katrien.verbert, erik.duval\}@cs.kuleuven.be

Short biographical sketches:

Dr. Joris Klerkx is a post-doctoral research expert at the Computer Science department of the Katholieke Universiteit Leuven in the research group Human-Computer Interaction (HCI). His research interests include user experience design (i.e. information visualization, facetted search, multi-touch, mobile devices), metadata, and flexible access to a global learning infrastructure based on open standards in general. Joris coordinated the research on educational content discovery in the EU eContentPlus project of ASPECT and has been furthermore involved in other EU eContentPlus projects of ICOPER, MACE and MELT. Currently, he's technical coordinator of the ARIADNE foundation and active in the CEN workshop on Learning Technologies.

Dr. Katrien Verbert is a post-doctoral researcher of the Research Foundation - Flanders (FWO) at the HCI research unit of the Katholieke Universiteit Leuven. Her research interests include content models, content reusability, context-aware recommendation and personalization, and applications thereof in technology enhanced learning, science information systems and music information retrieval. In that respect, she is currently 
involved with the RAMLET IEEE LTSC standardization project that is developing a reference model for resource aggregation. She is also involved with the EU FP7 project ROLE that is focusing on the issue of contextual recommendation as a basis to support the development of Responsive Open Learning Environments. A key element of the ROLE vision for PLEs is that they should be adaptive depending on the needs, preferences and skills of the learner. In this context, she is involved in research on usercentric and context-aware methodologies, technologies and systems for tracking learner interactions with content and tools. These interactions are used for data analysis and computing of personal, social and contextual information about users and applications that is used as a basis for recommendation. She co-organized the workshop on ContextAware Recommendation for Learning, at the Second Alpine Rendez-Vous in 2009 and the 1st workshop on Recommender Systems for Technology Enhanced Learning (RecSysTEL) that is jointly organized by the 4th ACM Conference on Recommender Systems (RecSys 2010) and the 5th European Conference on Technology Enhanced Learning (EC-TEL 2010).

Prof. Dr. ir. Erik Duval is a full professor ("hoogleraar") at the computer science department of the Katholieke Universiteit Leuven. Erik's research focuses on management of, and access to, structured and unstructured data. In practical terms, his research efforts mainly relate to repositories, federated search, harvesting, content management, but also more end user oriented aspects like information visualization, mobile information devices, multi-touch displays and mash-ups. His group typically applies research results to technology-enhanced learning, access to music and 'research2.0'. His current obsession is massive hyper personalization ("The Snowflake Effect") a topic on which he regularly keynotes. He is a member of the Scientific and Technical Council of the SURF Foundation, a fellow of the AACE, a member of ACM, 
Klerkx, Verbert \& Duval

and the IEEE computer society. He is on the Board of Editors of the Journal of Universal Knowledge Management; the Editorial Review Board and the Executive Advisory Board of the International Journal on E-Learning. 